\title{
La correspondencia entre Ricardo Palma y Nicolás de Piérola
}

\author{
Wilfredo Kapsoli Escudero \\ Universidad Ricardo Palma , Lima - Perú \\ wckapsoli@hotmail.com
}

\section{Resumen}

Las cincuenta y siete cartas y tres crónicas que escribió Ricardo Palma al presidente Nicolás de Piérola nos permiten comprender algunos aspectos esenciales propios de la Guerra con Chile, como el patriotismo del pueblo limeño, el saqueo de la Biblioteca Nacional, la marginación de la población indígena y el nacionalismo de Andrés Avelino Cáceres.

Palabras clave: Guerra con Chile, patriotismo, Biblioteca Nacional, población indígena y Andrés Avelino Cáceres.

\section{Abstract}

The fifty-seven letters and three chronicles that Ricardo Palma wrote to President Nicolás de Piérola allow us to understand some essential aspects during the War with Chile, such as: the patriotism of the people of Lima, the looting of the National Library, the marginalization towards the indigenous population and the nationalism of Andrés Avelino Cáceres.

Keywords: War with Chile, patriotism, National Library, indigenous population and Andrés Avelino Cáceres. 
Wilfredo Kapsoli Escudero, Doctor en Letras (Historia) por la Universidad Nacional Mayor de San Marcos. Posee estudios de posgrado en la Escuela Práctica de Altos Estudios de París. Ha sido becado por la Comunidad Científica Japonesa a la Universidad Nanzan de Nogoya. 


\section{Introducción}

La siguiente ponencia versa en torno a 57 cartas y 3 crónicas que Ricardo Palma envió a don Nicolás de Piérola entre 1880 y 1913. La lectura de este epistolario nos permite comprender pasajes oscuros y desconocidos de la historia nacional durante la trágica ocupación de Lima por el ejército chileno. De los múltiples temas y asuntos que comenta nuestro tradicionista al presidente Nicolás de Piérola, queremos resaltar cuatro asuntos capitales como son: l) El patriotismo del pueblo limeño; 2) El saqueo de la Biblioteca Nacional; 3) La denostación de la población indígena; y 4) El nacionalismo de Andrés Avelino Cáceres.

\section{Patriotismo del pueblo limeño}

"Ayer amanecieron dos banderas peruanas izadas, una sobre el cerro de San Bartolomé, otra sobre las ruinas del reducto de Vásquez" (Palma, 1964, p. 131)

¿Cuáles fueron las modalidades de la resistencia popular a la dominación chilena? Este es un tema, sin duda, apasionante que diseñaremos esquemáticamente. Habiendo estudiado la reacción y la conducta de las habitantes de Chiclayo y de la Sierra Central (cf. la bibliografía) podemos afirmar que la resistencia se manifestó pacífica y violentamente, sin contar las actitudes desbordantes en donde afloraron productos de odios raciales y de miseria lacerante.

Los chinos sufrieron no solo el saqueo de sus casas, fondas y bienes, sino que fueron asesinados por turbas enardecidas después de las derrotas de San Juan y Miraflores. En el Callao, muchedumbres hambrientas asaltaron los mercados y centros comerciales y, en fin, las pasiones acumuladas se desencadenaron frenéticamente en esos días aciagos. 
Los chinos se habían identificado plenamente con los invasores, marcharon con ellos hacia la toma de Lima. Su conducta es explicable por la violenta opresión a que habían sido sometidos por los propietarios antes del conflicto. Fue un instinto de clase que impulsó la actitud de los chinos. Por el mismo instinto también se lanzaron contra los chilenos en los días de la ocupación, como se desprende de estos dos casos.

En la noche del treinta y uno del mes próximo [marzo de 1881] como a las nueve horas pasado meridiano, un piquete de tropa del regimiento Curicó que perseguía a un asiático con el objeto de aprehenderlo, por sospechoso de hurto, fue acometido a balazos por un grupo de individuos de la misma nacionalidad que salían del teatro chino de esta ciudad y del callejón de Otaiza. Trabóse, con este motivo, entre los chinos y las tropas una ligera refriega de la cual resultaron muertos y heridos algunos asiáticos y un soldado del Curicó herido de bala, habiéndose tomado prisionero a más de quinientos chinos (Kapsoli, 1996, p. 147).

Los asiáticos Ajui y Acai fueron condenados a la pena ordinaria de muerte y José Tubá, Ypole y Ascensión Leufón, “a sufrir el castigo de cien palos y el resto de los prisioneros a que paguen una multa de cinco pesos y quince días de trabajos públicos" (Ibídem).

El 19 de setiembre de 1881, a las dos de la tarde fue asaltado, a inmediaciones de la Estación de Monserrate, el paisano [chileno] Dionisio Arenada por un grupo de asiáticos trabajadores del camal, dando por resultado la muerte de aquel, por varias heridas inferidas con instrumentos punzo cortantes y golpes de garrote y piedra (Ibídem, p. 148).

El jefe del Batallón Lontrue tomó "en ese sitio y en las inmediaciones a 22 asiáticos". Akiama "incitó a los chinos a que atacaran al Señor Oficial", Acuasi "tenía un garrote o pica 
ensangrentado" y Alelí que "estaba armado con armas de fuego, según expusieron los mismos aprehendidos”. Estos coolíes fueron sancionados con prisión y multas hasta de 200 pesos (Ibídem).

\section{Los editores de la calle Virreyna}

Los invasores "habían sojuzgado plenamente toda la prensa nacional. Ni en el Callao ni en Lima aparecía ningún periódico. Los habitantes recibían sus noticias solamente a través de las tres hojas redactadas por los chilenos: Situación, Día y Comercio" (Kapsoli, 1996, p. 220).

Por su parte, Ricardo Palma enfatiza la utilidad de la prensa para la causa nacional. Refiriéndose a El Canal (periódico properuano que se editaba en Panamá) decía:

En Lima se arrebatan y corren de mano en mano los números... sostener ese periódico no es tanto o más necesario que aumentar el ejército con un batallón. Como dijo no me acuerdo quién, la prensa es el cañón rayado de la inteligencia; y más barata en todo caso, que una batería de seis cañones Krupp y de efectos más seguros (Ibídem).

En la condición descrita, era obvio que no se podía alentar abiertamente ninguna publicación. Aún los empingorotados "murciélagos" civilistas embadurnados con don de peruanos fueron amonestados cuando hicieron circular una hoja suelta rotulada A los pueblos de la República. Ellos (Felipe Paz Soldán, Manuel A. Fuentes, José Bazagoita, Mariano Álvarez, Manuel Odriozola), que buscaban adherentes para el "Gobierno de La Magdalena”, fueron multados con 100 pesos (Ibídem).

Empero, dentro de aquel contexto, hubo gestos encomiables como los de Ricardo Palma, cronista y corresponsal de Piérola; 
de Abelardo Gamarra "El Tunante", de Luis Carranza, director de El Comercio, entre los más conocidos. Una acción más de apoyo y de divulgación patriótica fue la que asumieron los editores de la calle Virreyna. El parte consignado en el Libro de Sentencias del Tribunal Militar Chileno (02.12.1881) es tan elocuente que nos exime de todo comentario:

Vistos: el 18 de Noviembre del corriente año aprehendió la policía a dos individuos González y Guillermo Rojas que vendían en un portal de la Plaza Principal un folleto que contiene expresiones denigrantes y ofensivas al Ejército y Marina de Chile. De las indagaciones resulta que esa obra se imprimió en época anterior a la ocupación; pero cuya circulación se verifica ese mismo día y que en ella tenía parte los vendedores ya citados, Trinidad Domínguez administrador del establecimiento de encuadernación sito en la calle Virreyna $N^{\circ} 171$ y su propietario Juan Amecké. El número de ejemplares recogido ascendió a doscientos, de los cuales había veinticinco en poder de los vendedores. En mérito a estos antecedentes y teniendo presente el malicioso y culpable proceder de los citados individuos.

Acuerda: Condenar a Juan Amecké, alemán, casado y platero; a Trinidad Domínguez, peruano, casado y encuadernador; a Jorge González, colombiano, soltero y comerciante; y a Guillermo Rojas, peruano, soltero y comerciante, mayores de edad y reos del delito de circular publicaciones ofensivas e inmorales a la pena de prisión que sufrirán en la cárcel de esta ciudad, a contar desde el día que fueron aprehendidos, por un año el primero, conmutable en doscientos pesos; por seis meses el segundo, conmutable en cien pesos; y por tres meses el tercero y cuarto, conmutable en cincuenta pesos cada uno. Cúmplase. D. Fuenzalida E. del Canto Diego Donoso (Palma, 1964, p.149). 


\section{Los montoneros del valle de Yangas}

Derrotado el ejército nacional, destruida la armada naval, toda posibilidad de resistencia frontal era imposible. El general Cáceres, recuperado de las heridas recibidas en el campo de batalla, se internó en la Sierra Central donde organizó sus huestes indias con los que libró la memorable Campaña de la Breña. Una táctica móvil, sorpresiva y oportuna fue la modalidad de lucha que impulsó al mando de sus guerrilleros. Triunfos reconfortantes, crestas elevadas del nacionalismo inca fueron los combates de Sierra Rumi, Concepción, Sangrar.

Lima, corazón del país, situado y dominado por los chilenos estuvo presente también en la forja de montoneras de apoyo a Cáceres y de hostilización del enemigo. Se hacían colectas, se recababan armas, ropas y vituallas que, con mil ingenios, llegaban hasta los campamentos de los defensores de la Patria. De este apoyo logístico su expresión más grande fue la toma del ferrocarril que iba de Lima a Chilca y contó con el apoyo de hombres armados en las estaciones de Surco y Matucana.

En cuanto a los montoneros del valle de Yangas, bástenos transcribir el Acta de la Sentencia del Tribunal Chileno para comprender su significado. Hubo otros focos en Chosica, Naranjal y Matucana que no merecieron mayores comentarios.

En la ciudad de Lima a los veintisiete días del mes de Marzo de mil ochocientos ochenta y uno, reunido el tribunal Militar en la sala de su despacho, hizo comparecer a su presencia a los reos Raymundo Salinas y Manuel Ramírez, ambos peruanos, acusados de haber sido tomados prisioneros por una partida de caballería chilena, hallándose con las armas en la mano y formando parte de una montonera peruana hizo fuego contra dicha partida, Interrogados ambos sobre el particular, han prestado las siguientes declaraciones: 
Raymundo Salinas que pasaba por el paraje de Yangas en viaje a Canta el día veintitrés del actual y se detuvo a descansar en casa del comisario Manuel Soto; que encontrábase ahí oyó decir que se acercaba una montonera capitaneada por un tal Romero que pocos días antes había dado muerte a varios asiáticos y que el comisario reunió a algunos hombres para atacar a dicha montonera entre los cuales fue el declarante; que la partida llevó algunos rifles Peabody y se situó en un cerro inmediato que, poco después se vio aparecer del lado por donde se aguardaba la montonera tres o cuatro hombres montados que creyeron pertenecían a ella y les hicieron fuego, en seguida vieron venir detrás de los primeros un piquete de caballería y que habiéndose corrido la voz de que no era la montonera que esperaba sino tropa chilena, se dispersaron los que acompañaban al comisario, escapando todos menos los dos parecientes que fueron tomados prisioneros por la expresa fuerza de caballería y traídos a esta ciudad. Agrega que él disparó un solo tiro con su rifle (en Kapsoli, 1996, p. 230).

Manuel Ramírez confirma en todas sus partes la exposición anterior con la diferencia de que, según dice, trabajaba desde un mes en el fundo del comisario Soto y que hizo dos tiros sobre la tropa chilena. Ambos confiesan haber pertenecido al ejército regular del Perú, vencidos en Miraflores y Chorrillos, y dice que no se conocían el uno con el otro antes del hecho material de este juicio.

Llamados ante el Tribunal el Sargento Mayor don Belisario Campos y el Teniente de Cazadores a Caballo don Abel Ylabaca, que mandaba el piquete de caballería de que se ha hecho referencia, y juramentos en forma, ambos expusieron ser los reos presentes los mismos individuos que tomaron prisioneros el citado día veintitrés en el Valle de Yangas; que pasando por dicho valle en desempeño de una comisión de servicio con 
veinticinco hombres de cazadores, fueron atacados por una montonera peruana, compuesta de paisanos armados, que mandaba el comisionado del lugar, que habiendo hecho cargar a dicha montonera esta se dispersó y solo pudieron capturar a los reos expresados, armados de rifles, escapando los demás por los cerros y quebradas.

Teniendo en consideración que los citados reos se hallan convictos y confesos de haber hecho armas contra fuerza chilena, formando ellas parte de una montonera que no pertenece al ejército regular del Perú, el Tribunal por unanimidad de votos y con el dictamen del Fiscal ha condenado y condena a los reos Raymundo Salinas y Manuel Ramírez a la pena ordinaria de muerte, cuya sentencia deberá ejecutarse en el término de veinticuatro horas contadas desde aquella en que se ponga en conocimiento de los reos (Firmado: Letelier, González, Herreros).

En suma, la plebe limeña supo responder a su manera a la agresión chilena. Lo suyo no fue seguramente un nacionalismo elaborado o meditado académicamente. Fue más bien, práctico, activo. Mientras los miembros de las clases dominantes compartían la mesa y la cama con nuestros enemigos, los hombres del pueblo, humildes y anónimos, desmentían a Ricardo Palma quien descorazonadoramente exclamaba: "en el Perú el patriotismo es un mito" (Palma, 1964, p. 76).

\section{Saqueo de la Biblioteca Nacional}

Igualmente, en la carta $N^{\circ} 8$ del 29 de mayo de 1881, Palma vuelve a referirse a los sinsabores que le causa la Biblioteca Nacional estropeada por los chilenos invasores; textualmente dice: 
No son armas ni municiones lo que más necesitamos para escarmentar al enemigo chileno y vengar los pasados desastres. Es patriotismo y unión, ó lo que es lo mismo son

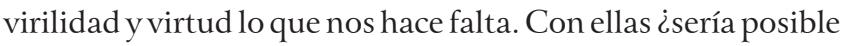
que Lima, ciudad de 130.000 almas, se encontrara sujeta por una guarnición chilena de 3,000 hombres? Es necesario que un pueblo haya llegado al colmo del envilecimiento para que, en cada diez individuos que encuentra uno por la calle, haya un espía asalariado por los chilenos ó un denunciante oficioso. Es necesaria mucha indignidad en un pueblo para que tolere la subsistencia de un partido ó circulito político, aliado del enemigo, y que festeja como triunfos propios las derrotas de nuestros montoneros y las matanzas de Cañete y las carreras de Pereyra en Huánuco.

El patriotismo sabe hacer milagros, es cierto; pero no hay que esperar milagros donde aquella virtud es casi negativa. Con ciento ó doscientos hombres abnegados y entusiastas como U. no se puede hacer más que cumplir con el deber hasta el sacrificio; pero es difícil alcanzar la victoria. Los buenos están en desconsoladora minoría. No son los chilenos que nos han vencido sino nuestros vicios, y consecuencia de ellos es la escasez de hombres para los puestos de compromiso. Padeció $\mathrm{U}$. la equivocación de creer que con la indulgencia se puede convertir en amigo al enemigo antiguo, y dió a los argolleros participación en la cosa pública. Así Man. Francisco Benavidez fué hasta Consejero de Estado, y no cito cien nombres más de civilistas conspículos. Pensó U. también que á los malos se les puede regenerar con el ejemplo de los buenos, que podía $U$. hacer de ellos hombres nuevos, fundirlos en molde nuevo é inspirarles la honorabilidad, el valor y la inteligencia de que primitivamente carecieron. Y resultado funesto de ese error fué el nombramiento del General Pata de Gallina, (I) cadáver sobre cuya tumba había yo puesto la losa inamovible del ridículo: ¿A qué, amigo mío, desenterrar muertos? (Ibídem, p. 94). 
Carta 4

En carta de R. Palma.

Lima, Marzo 10 de 1881

Lima, Abril 5/81

El Infrascrito, Director de la Biblioteca Nacional del Perú, tiene el honor de dirigirse á V.E pidiéndole haga llegar a conocimiento de su gobierno la noticia del crimen de lesa civilización cometido por la autoridad chilena en Lima. Apropiarse de biblioteca, archivos, gabinetes de física ó anatómicos, obras de arte, instrumentos ó aparatos científicos y de todo aquello que es indispensable para el progreso intelectual, es revestir la guerra con carácter de barbarie ajeno a las luces del siglo, a las prácticas del beligerante honrado y a los principios un iversal mente acatados del derecho.

La Biblioteca de Lima fue fundada en 1822, pocos meses después de proclamada la independencia del Perú, y se la consideró por los hombres de letras y viajeros ilustres que la han visitado como la primera entre las Bibliotecas de la América Latina. Enriquecida por la protección de los gobiernos y por obsequios de los particulares, contaba a fines de 1880 muy cerca de cincuenta mil volúmenes impresos y más de ochocientos manuscritos, verdaderas joyas bibliográficas, entre las que no escaseaban incunables o libros impresos durante el primer medio siglo posterior al descubrimiento de la imprenta y que, como V. E. sabe, son de inestimable valor; obras rarísimas hoy, esencialmente en los ramos de la Historia y Literatura; las curiosísimas producciones de casi todos los cronistas de la América española; y los libros regalados por los gobiernos extranjeros, entre los que figuraba el de V.E. con no despreciable contingente. Tal era, señor Ministro, la Biblioteca de Lima, biblioteca de que con justicia estábamos orgullosos los hijos del Perú. 
Rendida la capital el 17 de Enero a las fuerzas chilenas, trascurrió más de un mes respetando el invasor los establecimientos de instrucción. Nadie podía recelar, sin inferir gratuito agravio al gobierno de Chile, gobierno que decanta civilización y cultura, que para él serían considerados como botín de guerra los útiles de la Universidad, el gabinete anatómico de la Escuela de Medicina, los instrumentos de las Escuelas de Artes y de Minas, los Códices del Archivo Nacional ni los objetos pertenecientes a otras instituciones de carácter puramente científico, literario o artístico.

\section{Carta 8}

(Diputado Rospigliosi)

Lima, Mayo 29, 1881.

$\mathrm{R}^{\circ}$ Ayacucho, Julio 1 1/81-3p.

$\mathrm{C}^{\circ}$ Ayacucho, Agosto 24/81 -

Excmo. Señor Nicolás de Piérola.

Mi distinguido amigo:

Mientras estuvimos en Lima bajo la férula de D. Pedro Lagos, que era un borrachín-mujeriego, me tuvo Ud., como se dice, a salto de mata. Ese sujeto tuvo empeño en ponernos bajo sombra a Odriozola y a mí. El Ministro norteamericano intervino, y desapareció el conflicto personal. La protesta sobre el desbalijo de la Biblioteca exaltó la bilis del mandón chileno.

A propósito de la Biblioteca. El 25 se nos pasó orden calderoniana para volver a encargarnos de ella. Ya supondrá Ud. que, por mi parte, contesté rechazando corno debía el cargo. Siento decirle que mi amigo D. Manuel no quiso imitarme y que ha aceptado el puesto. Los chilenos han dejado en el establecimiento poco menos de tres mil volúmenes: infolios en pergamino, escritos en latín y casi todos sobre materias teológicas. Exceden de cuarenta y cinco mil tomos los que nos han robado. 
Ya sabrá Ud. que el Provisorio de la Magdalena ha recibido de Panamá siete millones, según unos, y once según otros, en billetes de banco. De ellos ha entregado dos millones a los chilenos en pago de los dos meses de contribución. Tenemos, pues plétora de papel.

En cuanto a Congreso, las uvas están verdes, verdísimas. Hasta ahora solo cuenta en Lima con setenta y cinco representantes, entre Senadores y Diputados, faltándole treinta y ocho de los últimos para que esa Cámara complete quorum. De Puno ha llegado un Señor Eduardo, burlando la vigilancia del Prefecto; mas esperamos que haya mayor cuidado en los otros departamentos del Sur para impedir que los carneros civilistas vengan a la querencia de Chorrillos. Los anti-argolleros, Macedo y Saavedra han concurrido a las juntas preparatorias y los acaba de seguir (imaravíllese Ud!) nuestro amigo Jiménez a quien siempre tuve por honrado, patriota e inteligente. No se a qué expediente o embolismo recurrirán paro completar número.

Aseguran los calderonianos que Lynch les ha ofrecido retirarse con las tropas al Callao, tan luego como instalen Congreso. De este modo, dicen, cesará Lima de estar sujeta a la ley marcial, podrán funcionar los Tribunales, y acaso seremos reconocidos por la Suprema y por el Cuerpo Diplomático.

El único representante que ha observado un procedimiento digno y enérgico es D. Pedro Tirso Valdez, Senador por Ica. Requerido para asistir a las Juntas, ha contestado oficialmente que carece de representación, por cuanto su Departamento no reconoce al Gobierno de la Magdalena.

¿Qué daño le ha inferido U. al ilustrísimo Tordoya para que le haya declarado guerra sin misericordia? Dice que transigirá con el diablo antes que con U. 
La "Actualidad" ha cesado de publicarse desde el 27. Es el caso que su redactor Errázuris es exaltado partidario de SantaMaría, y que Lynch es furioso baquedanista. Llegó á noticia de Lynch que, en esa imprenta, se estaba trabajando muy seriamente un folleto contra Baquedano, en el cual, entre otras lindezas, se decía que el General huyó á las dos y media de la tarde del campo de Miraflores y que volvió á él después de las cuatro, cuando ya tenían ventaja los chilenos, gracias a los esfuerzos y disposiciones de Maturana y Vergara. Para impedir que aparezca el panfleto decidió Lynch quitarle la imprenta á Errázuris, y las máquinas y tipos se están encajonando para remitirlos á Santiago. No obstante, me aseguran que el folleto, del cual estaban ya impresos varios pliegos, aparecerá pronto para circular solo en Chile. Es posible que llegue yo á conseguir un ejemplar, y cuidaré de enviarlo á $U$.

El triunfo de la candidatura Santa-María es segurísima, y lo siento. Habría preferido que Baquedano triunfase. Este ganará la elección solo en Santiago y en Rancagua. En el resto de Chile está derrotado, y aun en Santiago no es imposible que lo venzan.

En nuestra indolente y perezosa Lima no se mueve una paja. Nadie se ocupa de Calderón y sus magdalenos. Son como si no existieran. En cuanto a los chilenos, parece que empezamos á habituarnos con la permanencia de ellos, tanto que ya se han celebrado cuatro ó cinco matrimonios limeños. iDesventurada tierra! Aquí está el pueblo resignado con su ignominia y nada quiere hacer por sacudirla. Lejos de eso, abundan los espías y denunciantes que van con chismes á la autoridad chilena. 


\section{Denostación de la población indígena}

En lo concerniente a los comentarios de Ricardo Palma sobre la población indígena, tenemos que dejar bien claro que sus opiniones son francamente lamentables. En la carta $\mathrm{N}^{\circ} 2$ dirigida a Don Nicolás de Piérola el 8 de febrero de 1881 leemos:

Llegó la hora de la prueba, y los hombres rehuyeren cumplir con su deber, y no encontró Ud. un hombre que supiera ayudarlo, y hasta sus edecanes dieron muestras de ruindad abandonándolo miserable y cobardementemente a los primeros disparos del enemigo. ¿A qué ambicionaban ciertos hombres altos puestos y mando de soldados, si no se sentían con coraje para batirse? He aquí uno de los frutos de la corrupción social: por esos menguados cosecha la nación luto é ignominia.

Como me decía Ud. muy juiciosamente una mañana —en que tuve el honor de almorzar en su compañía-: aquí no hay sino desquiciamiento, inmoralidad y cobardía, y sobre todo, gran escasez de hombres.

En mi concepto, la causa principal del gran desastre del 13 está en que la mayoría del Perú la forma una raza abyecta y degradada, que Ud, quiso dignificar y ennoblecer. El indio no tiene el sentimiento de la patria; es enemigo nato del blanco y del hombre de la costa y, Señor por Señor, tanto le da ser chileno como turco. Así me explico que batallones enteros hubieran arrojado sus armas, en San Juan, sin quemar una cápsula. Educar al indio, inspirarle patriotismo, será obra no de las instituciones sino de los tiempos.

Por otra parte, los antecedentes históricos nos dicen con sobrada elocuencia que el indio es orgánicamente cobarde. Bastaron 172 aventureros españoles para aprisionar a 
Atahualpa, que iba escoltado por cincuenta mil hombres, y realizar la conquista de un imperio cuyos habitantes se contaban por millones. Aunque nos duela declararlo hay que convenir en que la raza araucana fué más viril, pues resistió con tenacidad a la conquista. (Palma, 1964, p. 13)

Si Ricardo Palma nos sorprende a nosotros con sus ignominiosas conjeturas, Bernard Lavalle ya había reparado esta actitud en su ensayo "Los temas indios en las Tradiciones Peruanas" donde dice:

El lugar que ocupan los indios es bastante reducido. De aproximadamente 500 tradiciones, solamente en unas treinta figuran como protagonistas o se les otorga un papel simple de acompañantes o extras, formando parte de la ambientación.

La distribución de estas tradiciones "indígenas" suscita algunas observaciones. El período prehispánico que se toma en tres oportunidades, se representa de manera muy somera. Este además fue descuidado muy pronto y desaparece después de la tercera serie (1875). Asimismo, la época republicana y la independencia apenas intervienen en tres anécdotas indias: dos escritas por un Ricardo Palma aún joven $\left(1^{\mathrm{a}} \mathrm{y}\right.$ $2^{a}$ series, 1872-1874) y una tercera un poco más tardía $\left(7^{\mathrm{a}}\right.$ serie, 1899). Lo esencial, aproximadamente 5 partes de 6 , presenta como marco histórico el coloniaje con una marcada preferencia por el siglo XVI (13) y por el siglo XVIII (8). El siglo XVII, muy rico además, apenas presenta cuatro.

Si se establece, por otra parte, la cronología en la que aparecen estas tradiciones, según las series en las que figuran -aunque esta referencia no sea totalmente válida- se constata que las cuatro primeras series y la quinta, publicadas en 1883 pero redactadas principalmente antes de la Guerra del Pacífico, reagrupan 21 de estas tradiciones, es decir, las dos terceras 
partes. Por consiguiente, mientras que la derrota ante Chile y sus consecuencias iban a despertar un nuevo interés por la problemática indígena, tanto en la política como en la literatura así como un análisis radical, cuando R. Palma, convertido en la figura emblemática de las letras peruanas había escrito más de la mitad de sus tradiciones, se puede observar que este mostraba un marcado desinterés por estos temas que solo aparecen cuatro veces en la $7^{\text {a }}$ serie (1889) y dos veces en la $8^{\text {a }}$ serie (1891) y en la $9^{\text {a }}$ serie (1899). Entonces, no se trata en esta última serie solo de alusiones a los indios respecto a uno u otro conquistador... Finalmente, la $10^{\text {a }}$ serie también presenta dos tradiciones indígenas, pero una de ellas es solamente la publicación, después de casi medio siglo, de una obra escrita a la edad de 19 años y va acompañada de una nota en la que este viejo escritor la presenta "con mucho afecto" como una curiosidad de su juventud (Lavalle, 2018, pp. 127-128).

\section{Nacionalismo de Andrés Avelino Cáceres}

En la carta $N^{\circ} 11$ de fecha 22 de julio de 1881 leemos lo siguiente:

["Andrés A."] Cáceres, situado en Matucano, ha puesto en jaque á chilenos y achilenados. Presumo que para setiembre habrá U. organizado y puesto en movimiento un ejército respetable, y que para entonces hará la intimación del caso al enemigo. O paz decorosa o guerra sin tregua. Pero en Sus cálculos, amigo mío, proceda U. sin contar para nada con Lima. Aquí la gran mayoría es de indolentes que desean sacudir el yugo chileno; pero sin poner ellos nada de su parte. Como las beatas con sus oraciones, lo ayudarán á U. con sus simpatías y con habladurías callejeras; pero nada más. Tendrá U. muchas, muchísimas promesas y hasta combinaciones y planes atrevidos para secundar 
oportunamente las operaciones militares que U. emprenda acercándose á la capital; pero en el momento preciso hallará pocos hombres y abundancia de bribones, y cobardes. La semilla de los Pata de Gallina, Osma, Canseco y Rivarola ha fructificado abundosamente.

Mucho avanzaremos con la inauguración, en Setiembre, del nuevo gobierno en Chile. Santa María sube al poder como quien tiene bajo sus plantas una bomba con dinamita. Juzgue U. por el recorte impreso que le incluyo, ya que periódicos chilenos no llegan aquí á poder de ningún peruano. Parece que desean que no conozcamos el espíritu de su prensa, ni nos formemos cabal concepto de la efervescencia de los partidos. Pero el hecho es que se aglomeran nubes y que la tempestad vendrá.

Para conjurar la borrasca, para evitar el incendio de la propia casa, tendrá Santa María que hacer lo posible por poner término al conflicto con el Perú. Al cabo se convencerá de que paz con cesión de territorio, será paz firmada sobre arena: de que paz en que, en materia de armamento y desarme, nos colocáramos bajo el tutelaje de Chile, sería una paz imposible por absurda.

A Santa María no puede escondérsele que no es obra de romanos el batir al ejército de ocupación que hoy existe en Lima, y que vá á ser reforzado con cuatro ó cinco mil hombres más. Sabe también que si acepta el plan propuesto en el seno de las Cámaras de abandonar Lima y reconcentrar su ejército en Tarapacá, tendrá allí que mantenerlo á la defensiva indefinidamente, pues la guerra se haría eterna. Añade U. que el enemigo debe estar escarmentado del éxito de los bloqueos y de la ineficacia de estos en costa tan abierta como la nuestra y ainda mais tan dilatada. 
El hecho es que, después de dos años largos de guerra y de la ocupación de Lima, se encuentra ahora Chile con que la guerra empieza. El cansancio tiene que entrar por algo en las probabilidades de paz, pero paz en que Chile, para no exponerse á perderlo todo, consienta en amainar algo de sus exageradas pretensiones.

Por nuestra parte, en el ensayo "El nacionalismo indígena en la Guerra con Chile" (2011) hemos abundado en la gloriosa resistencia andina a la invasión chilena de nuestro territorio.

\section{El nacionalismo indígena en la Guerra con Chile ${ }^{1}$}

¿Tuvieron los indígenas una conciencia nacional durante la guerra? ¿Fueron las guerrillas manifestaciones de aquel nacionalismo? ¿Pelearon por el Perú o lo hacían por Piérola, Cáceres o Iglesias?

Estas y otras preguntas han motivado una serie de debates e investigaciones. Los artículos de Henri Favre, Florencia Mallon y las tesis de Heraclio Bonilla y de Nelson Manrique constituyen los trabajos más representativos al respecto. FavreBonilla niegan el brote de una conciencia nacional indígena, priorizan los problemas étnicos (guerra de castas) y de clase; por el contrario, Mallon-Manrique son fervientes defensores del nacionalismo indígena y del perfil antiterrateniente de la lucha campesina (Kapsoli, 201 1, párrs. 1-2).

¿Cuál de los planteamientos se acerca más a la realidad? ¿Hacia dónde inclinarnos? Las réplicas que hace Manrique a Favre por su inconsistencia documental y su falta de correspondencia cronológica no han sido contestadas. Pero las observaciones que

1 Esta sección reproduce parte del ensayo de nuestra autoría "El nacionalismo indígena en la Guerra con Chile" (2011). 
hace Bonilla a Manrique sobre cómo se estableció el deslinde entre la conciencia campesina y la conciencia nacional, qué mecanismos operaron el cambio de la conciencia nacional a la de los intereses de clase, tampoco han merecido respuesta. ¿Habrán dado por concluidas aquellas preocupaciones o más bien estarán acumulando datos y afinando ideas para la polémica? No lo sabemos.

Por nuestra parte, creemos que en todo el debate anterior hay una serie de ideas rescatables y algunas constataciones evidentes. Pero se notan generalizaciones apresuradas a partir de algunos casos y la falta de una compulsa mayor de las fuentes e informaciones. Quizá por ello pasaron por alto el nacionalismo indígena que, durante la guerra, se personifica en las figuras de Tayta Cáceres y de Tomas Laynes: un nacionalismo inca.

Un soldado chileno representante de Aconcagua, refriéndose a los indígenas dice: “... impórtales nada que gobierne el Perú Sancho, Pedro o Juan, pues, siempre ellos, conservando instintivamente las tradiciones de sus mayores, se creen los humildes súbditos de algún poderoso Inca" (Kapsoli, 201 1, párrs. 3,4,5).

Antonia Moreno consigna en sus memorias:

Para los indios, Cáceres era de reencarnación Inca; por eso se postraban delante de él. Ellos creían que Cáceres era el continuador de sus antiguos señores los Incas y siempre que lo veían le querían rendir homenaje, mezcla de cariño y gratitud. Le llamaban Tayta (padre, señor), con tanto cariño que conmovía. Por eso en Pucará, pueblo de la sierra central, lo recibieron a la usanza del antiguo imperio del Sol. Lindas comparsas de indios, lujosamente vestidos, bailaban a su alrededor cantando y arrojando mixtura de fragantes pétalos sobre nuestras cabezas y sobre el suelo que pisámos". Algunos estaban disfrazados, enmascarados 
daban fuetazos en el aire y se movían alegre y lujosamente (en Kapsoli, 2011, párr 6).

Otro testimonio enfatiza la popularidad y ascendencia de Cáceres:

Los indios lo consideran ser superior. Se descubren desde que lo divisan y se arrodillan en su presencia. A cada cual le habla en su lengua natural y les asegura que defenderá sus chozas y que nadie tocará sus llamas y carneros (Ibíd., párr. 7).

Los pueblos anuncian con anticipación su paso. Lo reciben con repique de campana, cohetes y toques de bombo, tamboril y cuerno. A su llegada bailan, danzan con música de arpa, guitarra y violín. Cantan los huaynos o canciones de guerra. Las mujeres le presentan sus niños y es para ellos timbre de gloria que el Tayta toque la cabeza de sus guaguas. Es el Inca, el encargado de protegerlos contra los blancos (Íd.).

La idea de protección que recibirían se acentuaba con la agresión, los cupos y la violencia que los chilenos imprimían a las poblaciones indias. Por ello, por su atavismo,

rendían homenaje a la pachamama y al verla hollada, vejada, sentían revivir en sus corazones el viejo orgullo de los legendarios hijos del sol y, así como en aquellas épocas ancestrales combatían bravamente por su noble señor, se ofrecían en holocausto por la patria y por el Tayta que era el alma de la resistencia nacional (Ibíd., párr. 8).

Cáceres mismo contaba que en algunos pueblos de la sierra guardan la poética y vieja tradición de saludar al Sol: “cuando el astro aparece, ellos se inclinan profundamente, quitándose el sombrero"(Ibíd., párr. 9).

En diversos momentos de adversidad y de infortunio, la fuerza de su identificación con el Tayta reconfortó el ánimo de los 
guerreros. Así, después del desastre de Julcamarca, ocasionado por una espantosa tempestad, los gritos de iViva el Perú! iViva el Tayta Cáceres! retumbaron los cerros y alentaron a los que habían sobrevivido.

Pero también los condujo al fanatismo. Cáceres, refiriéndose a un combate de avanzada, afirmaba: "Ignoro las bajas del enemigo. Sólo he visto con impresión algunas cabezas de ellos en las puntas de lanzas que los indígenas traían como trofeos de guerra". Igualmente, un diario de la época comenta:

Al entrar el General Cáceres a Acostambo fue recibido por los indios con gran entusiasmo. La mayor parte ostentaba en la punta de sus lanzas las cabezas y miembros mutilados de los chilenos muertos en combate. En las paredes de las casas y en los muros de las chacras se divisan también los mismos trofeos sangrientos, recordando los horrores de la guerra de la Edad Media (Ibíd., párr. 11).

Durante toda la resistencia Cáceres recibió la colaboración de los indígenas. Siendo ésta más intensa en algunos departamentos, como Junín, Ayacucho y Huancavelica, fue prácticamente inexistente en Ancash, Cajamarca y la Libertad. El nacionalismo inca en estas regiones no se había puesto en evidencia tampoco en las épocas anteriores. En Ancash, es posterior a la guerra el levantamiento de Atusparia y su inmolación por "El Sol de los Incas”. Sin embargo, Daniel de los Heros recuerda el apoyo que recibieron de los indios de Chacabamba:

Se subió una cuesta bastante larga para llegar a Sulluyacu que está en una altura. Los indios de las vecinas estancias vinieron trayendo comida para el General; carne, papas y maíz para la tropa, que ellos mismos cocinaron en la noche. Se conocía el gusto con el que atendían a nuestros soldados esos pobres indios, guiados solo por el noble impulso de 
su noble corazón por instinto de amor patrio que no se borra en las almas puras, pues, su ignorancia no les permitía comprender la elevada misión que nuestro ejército tenía que cumplir (Ibíd., párr. 12).

El General Cáceres fue, sin duda, un hombre de carisma. Supo aprovechar y representar el sentimiento andino. El trato, la familiaridad, la preocupación por “sus hijos" le confirió el liderazgo mayor. A los soldados los asistía personalmente en los ejercicios y, a menudo, los dirigía él mismo. "Esto regocijaba a la tropa y a mí me proporcionaba la coyuntura de conocerlo individualmente", anota. A los indios les hablaba en lengua quechua y los convertía en mansos corderos. Tenía gran dominio sobre los indios, hablaba todos los dialectos provinciales, conocía la idiosincrasia local. Había pasado su infancia en Ayacucho. Daba prestancia a su ascendencia materna de Justa Dorregaray Cuevas, de la princesa Catalina Huanca, último vástago de la estirpe de los Incas (Ibíd., párr. 13).

Durante la guerra con Chile, los indígenas actuaron también motivados por el nacionalismo indiferenciado de hacendados, curas, alcaldes y comerciantes. Sobre todo, muchos peones de hacienda asumieron el papel que sus patrones tomaron durante la guerra. Así pelearon en San Juan y Miraflores, al lado de sus dueños los labradores de Montán, de Tucle, Antapongo, de Sollaeta. Pero esos mismos hacendados, Iglesias y Vadallares, posteriormente los hicieron combatir a favor de los chilenos (Ibíd., párr. 14).

\section{Bibliografía}

Kapsoli, W. (1984). Chiclayo en la coyuntura de la Guerra del Pacífico. Lima: Editorial Universidad San Marcos.

Ed. Lumen.

. (1996). Modernidad y tradición. Perú, siglos XVI - XX. Lima: 
- (2011). "El Nacionalismo Indígena en la Guerra con Chile”. En Andrés Avelino Cáceres. Recuperado de: http://taytacaceres. blogspot.com/201 1/03/el-nacionalismo-indigena-en-la-guerra.html . (1992). Nacionalismo Inca. Lima: Ed. Purej.

Lavalle, B. (2018 [1973]). "Los temas indios en las Tradiciones Peruanas de Ricardo Palma", en: Pludiversidad $N^{\circ} 1$. Lima: Universidad Ricardo Palma.

Palma, R. (1964). Cartas inéditas. Lima: Ed. Carlos Milla Batres.

Recibido el 10 de marzo del 2019 Aceptado el 13 de marzo del 2019 